
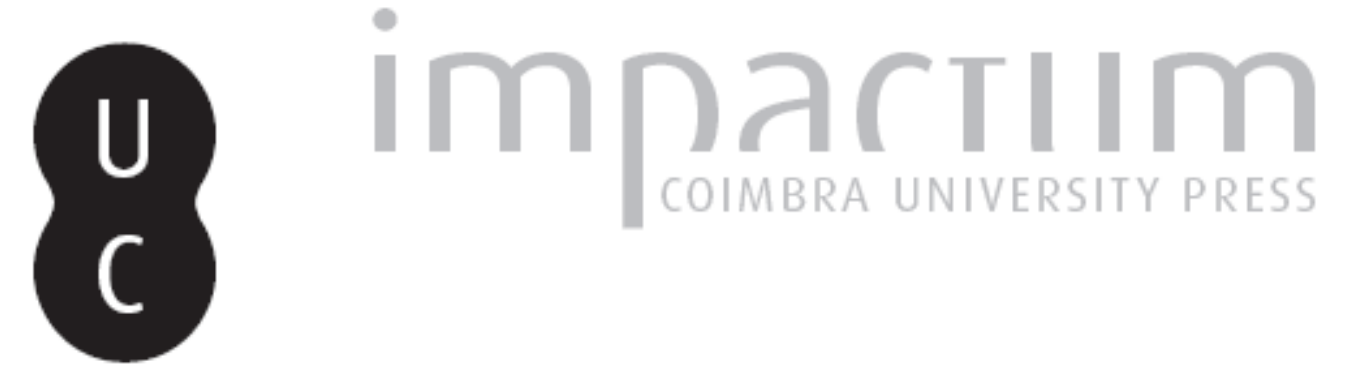

\title{
A idade da inocência: uma cidadania globalizada no eclipse do político
}

\section{Autor(es): $\quad$ Sá, Alexandre Franco de}
Publicado por: Faculdade de Letras da Universidade de Coimbra, Instituto de Estudos Filosóficos

URL persistente:

URI:http://hdl.handle.net/10316.2/33332

DOI:

DOI:http://dx.doi.org/10.14195/0872-0851_37_3

Accessed : $\quad$ 26-Apr-2023 15:16:03

A navegação consulta e descarregamento dos títulos inseridos nas Bibliotecas Digitais UC Digitalis, UC Pombalina e UC Impactum, pressupõem a aceitação plena e sem reservas dos Termos e Condições de Uso destas Bibliotecas Digitais, disponíveis em https://digitalis.uc.pt/pt-pt/termos.

Conforme exposto nos referidos Termos e Condições de Uso, o descarregamento de títulos de acesso restrito requer uma licença válida de autorização devendo o utilizador aceder ao(s) documento(s) a partir de um endereço de IP da instituição detentora da supramencionada licença.

Ao utilizador é apenas permitido o descarregamento para uso pessoal, pelo que o emprego do(s) título(s) descarregado(s) para outro fim, designadamente comercial, carece de autorização do respetivo autor ou editor da obra.

Na medida em que todas as obras da UC Digitalis se encontram protegidas pelo Código do Direito de Autor e Direitos Conexos e demais legislação aplicável, toda a cópia, parcial ou total, deste documento, nos casos em que é legalmente admitida, deverá conter ou fazer-se acompanhar por este aviso.

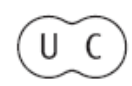




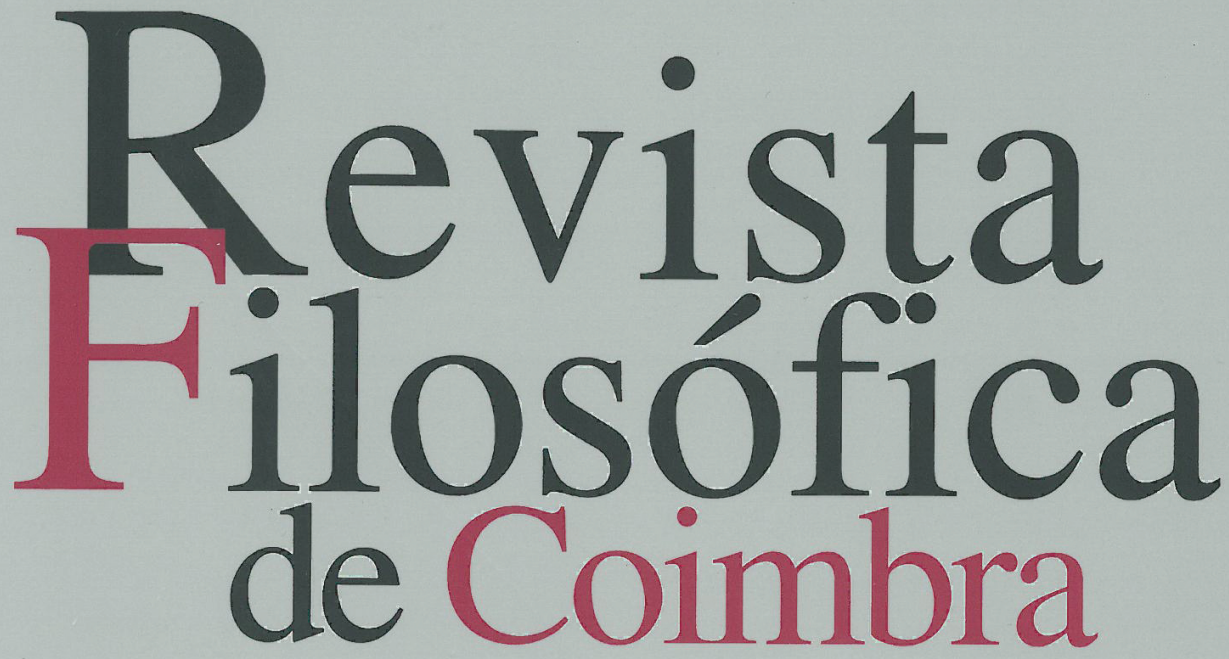

vol.19|n. $.37 \mid 2010$

Maria Luísa Portocarrero Mário Santiago de Carvalho Alexandre Franco de Sá Luís António Umbelino Luís G. Soto José Filipe Silva Joaquim Braga Maria da Conceição Camps Pedro Miguel Panarra Immanuel Kant 


\title{
A IDADE DA INOCÊNCIA: UMA CIDADANIA GLOBALIZADA NO ECLIPSE DO POLÍTICO ${ }^{1}$
}

\author{
ALEXANDRE FRANCO DE SÁ*
}

Resumo: Partindo do problema de uma circunscrição do conceito de globalização a partir de uma perspectiva filosófica, caracterizando a globalização a partir do conceito heideggeriano de Zuhandenheit e do conceito jüngeriano de totale Mobilmachung, o artigo propõe-se considerar o significado político da globalização a partir da ideia de redução das escolhas e dos conflitos políticos a escolhas e conflitos entre possibilidades que não são diferentes senão na aparência. A partir desta consideração, o artigo aborda problemas decorrentes deste fenómeno na sociedade actual: a crise da deliberação e o poder mediático, a crise educativa e a transformação das democracias ocidentais naquilo a que é aqui chamado "oligarquias cacocráticas".

Palavras-chave: Globalização, política, democracia, decisão, deliberação, educação.

Abstract: Starting from the problem of circumscribing the concept of globalization from a philosophical point of view, and characterizing globalization from the perspective of Martin Heidegger's concept of Zuhandenheit and Ernst Jünger's concept of totale Mobilmachung, the article argues that the political meaning of globalization lies in the reduction of political choices and conflicts to choices and conflicts between possibilities that are only apparently different. Taking this in account, the article approaches problems in nowadays societies which emerge from this phenomenon: the crisis of deliberation and media-power, the crisis in education and the transformation of occidental democracies in what here is called "cacocratic oligarchies".

Keywords: Globalization, politics, democracy, decision, determination, education.

\footnotetext{
* Departamento de Filosofia, Comunicação e Informação (Faculdade de Letras da Universidade de Coimbra).

${ }^{1}$ Conferência apresentada no XI Simpósio da Associação Iberoamericana de Filosofia Política, em Bahia Blanca (Argentina).
} 
Com o fim da divisão da Europa em dois blocos políticos antagónicos, impôs-se no mundo ocidental, com uma veemência crescente, aquilo a que se poderia chamar - usando uma terminologia inspirada em Ortega y Gasset - a crença fundamental que animou, como seu pano de fundo, a vida política do Ocidente nos últimos vinte anos. Uma tal crença deriva da verificação de que a crise e o desmantelamento dos Estados de inspiração soviética na Europa, e o fim da era que foi caracterizada como a "Guerra-fria", teve como consequência a inauguração de uma nova era determinada pela aceleração e consumação de um processo de progressiva unificação do espaço planetário, processo esse que já estaria em curso, afinal, desde o início da era moderna. É a um tal processo de unificação, subjacente a uma multiplicidade de fenómenos empíricos que se estendem por diversos âmbitos - financeiro, económico, social, político, tecnológico, informativo -, que poderemos chamar aqui genericamente "globalização". No âmbito sociológico, a globalização constitui um tema complexo, descrito de forma muito diferente segundo a diferente avaliação que é feita da variedade dos fenómenos que lhe são associados. É por isso que, neste âmbito, a globalização pôde ser abordada tanto a partir das oportunidades que despoleta - tendo em conta a actual velocidade da informação, a facilidade de circulação, a progressiva interdependência entre os Estados ou a consciência em torno dos problemas comuns da humanidade - como a partir dos riscos e dos problemas que arrasta consigo, desde a falta de ordenamento político dos mercados globais até à desprotecção da pobreza ou à exploração descontrolada e devastação dos recursos naturais do planeta. No entanto, seja como for que as consequências empíricas da globalização sejam apresentadas, e o próprio processo de globalização em função de tal apresentação - avaliado, é face às diferentes abordagens sociológicas, todas elas concentradas numa reflexão sobre um plano empírico, que uma perspectiva filosófica poderá contribuir com uma visão, à partida, mais simples e conceptual sobre o sentido político da globalização. Tendo em conta uma tal perspectiva, poder-se-á dizer que a globalização não pode deixar de aparecer essencialmente ligada a uma unificação do espaço do mundo. Esta unificação é, poder-se-ia dizer, a sua ratio essendi. E é tendo em conta esta sua ratio essendi que se pode compreender o surgimento da crença que lhe está ligada: a crença naquilo a que se poderia chamar um processo imparável de "despolitização" do mundo. Dir-se-ia que, se da vida política é próprio um afastamento e uma separação entre os homens em virtude das várias comunidades a que pertencem, e se à dimensão do político é essencial o antagonismo e a possibilidade do conflito, ou seja, se - para fazer uso de uma expressão de Carl Schmitt na apresentação do seu "conceito do político" - «o mundo 
político é um pluriverso, não um universo ${ }^{2}$, então a globalização, pensada a partir da tentativa de captar a sua essência, pensada a partir da unificação do espaço planetário e da velocidade de circulação de capitais e bens, de pessoas e de informações por ela despoletada, não pode deixar de gerar a crença num imparável processo de abatimento de fronteiras e de separações políticas que consuma a emergência de uma era caracterizável como pós-política.

A caracterização da globalização como a introdução de um processo de despolitização pode, naturalmente, suscitar a objecção de que tal caracterização pressupõe uma compreensão demasiado tradicional, ou mesmo obsoleta, do "conceito do político". Uma tal objecção diria o seguinte: se o político for compreendido, numa perspectiva schmittiana, como a possibilidade de diferenciar soberanamente entre o amigo e o inimigo $^{3}$, e se a política for tida como consistindo no mundo do exercício unilateral do poder e da soberania, no mundo de conflitos e de guerras, gerado por tal possibilidade, facilmente se poderia caracterizar a superação deste mesmo mundo como um eclipse do político ou como a introdução de uma era pós-política; no entanto, mais do que caracterizar a nossa era a partir de um processo de despolitização, e de desactualização dos conceitos políticos fundamentais, seria certamente mais adequado falar numa reconfiguração da política, ou seja, numa "nova política" e, portanto, numa nova significação dos seus conceitos. É esta a atitude teórica de autores como, por exemplo, Ulrich Beck, falando no aparecimento de uma "sub-política" marcada não apenas pela despolitização das dimensões políticas tradicionais, mas também, ao mesmo tempo, pela concomitante politização de dimensões da vida humana tradicionalmente consideradas não políticas: «A constelação política da época industrial torna-se impolítica, enquanto aquilo que no industrialismo era impolítico se torna político» ${ }^{4}$. Assim, longe de sustentar o diagnóstico superficial de um fim da política, ou de um puro e simples surgimento de homens anestesiados, egoístas e alheados de causas públicas, tais autores chamam a atenção para o facto de que se trata hoje não tanto de uma despolitização, mas de uma "nova política" na qual os Estados, os partidos e as elites políticas tradicionais já não monopolizam o protagonismo, mas aparecem poderosas e inesperadas iniciativas, em defesa de causas comuns ou filantrópicas, por parte de actores políticos anónimos ou indefinidos. Como conclui Beck: «O fenómeno dos anos oitenta que é socialmente espantoso, surpreendente, mas muito pouco concebido, é a inesperada renascença de uma

\footnotetext{
2 Carl Schmitt, Der Begriff des Politischen, Berlim, Duncker \& Humblot, 1996, p. 54.

${ }^{3}$ Cf. Ibid., pp. 26 ss.

${ }^{4}$ Ulrich Beck, Die Erfindung des Politischen, Frankfurt, Suhrkamp, 1993, p. 157.
} 
subjectividade política - fora e dentro das instituições. Neste sentido, não é exagerado dizer: as iniciativas dos cidadãos conquistaram tematicamente o poder» ${ }^{5}$. Diante das objecções pertinentes de que se trata hoje não tanto de uma despolitização mas de uma "nova política" socialmente prevalecente, e para não cair numa discussão meramente terminológica em torno do que se entende por política, poderíamos dizer que aquilo que procuramos descrever através do conceito de despolitização corresponde, no fundo, ao advento desta "nova política" e desta "nova cidadania". Como se pode caracterizar esta "nova política" que, à luz de uma concepção tradicional da política, se poderia descrever como uma despolitização? Eis a pergunta que aqui pode nortear a nossa reflexão.

Para começar uma abordagem desta "nova política" e desta "nova cidadania" que se impõem a partir daquilo a que chamámos a despolitização enquanto crença fundamental das nossas sociedades democráticas, importa considerar, antes de mais, que o processo de globalização que lhe está na base, compreendido como um processo de redução progressiva do mundo a uma rede à qual tendencialmente tudo se encontra conectado, é apresentado como um movimento crescente, inevitável e ininterrupto. Ao longo do século XX, a representação de um mundo constituído como uma rede de remissões aparece sobretudo no pensamento fenomenológico de Martin Heidegger. Segundo o Heidegger de Ser e Tempo, o "mundo" não é um ente nem uma totalidade ôntica de entes, mas é justamente aquilo cuja estrutura unitária, subjacente à totalidade dos entes, permite que cada um seja o que é na quotidianeidade da nossa relação com ele. As considerações de Heidegger em torno do ente a que chama "à-mão" (Zuhandenes), o qual é o que é a partir de uma teia global de relações, conexões e remissões, permite precisamente compreender o mundo como um espaço global, unificado em rede e em que tudo se torna mais próximo. É isso que permite a Heidegger afirmar que «aquilo que está à-mão, na lida quotidiana, tem o carácter da proximidade» ${ }^{6}$. Contudo, para além de Heidegger, que analisou estaticamente esta proximidade, são as reflexões de Ernst Jünger em torno de uma "mobilização total" que estende gradualmente ao mundo um "carácter total de trabalho" que privilegiadamente permitem pensar a unificação global do espaço planetário como um movimento inevitável e crescentemente total. Se Heidegger tinha pensado o "mundo" como uma totalidade relacional que nada deixa fora da sua estrutura unificadora, Jünger vê na unificação do espaço planetário através daquilo a que chama uma "mobilização total", movida pela técnica, um processo irresistível a que ninguém pode escapar. É por isso que, para

\footnotetext{
${ }^{5}$ Ibid.

${ }^{6}$ Martin Heidegger, Sein und Zeit, Tübingen, Max Niemeyer, 1986, p. 102.
} 
Jünger, diante da unificação técnica do espaço planetário numa totalidade global, a procura de um espaço desligado ou retirado já não corresponderia senão a uma fuga romântica cuja possibilidade estaria simplesmente prestes a desaparecer. Como se lê em $O$ Trabalhador, de 1932, numa descrição eloquente: «No seu afastamento do presente temporal, a situação do espaço romântico aparece como passado, e como um passado colorido pelo sentimento reactivo (ressentiment) contra o estado vigente no momento. $\mathrm{O}$ afastamento do presente espacial apresenta-se como a fuga de um espaço completamente seguro e penetrado pela consciência, e daí que o número das paisagens românticas se dissolva numa relação proporcional com a marcha triunfal da técnica enquanto mais agudo meio da consciência. Ainda ontem elas talvez estivessem "longe, na Turquia", ou na Espanha e na Grécia; ainda hoje, na zona de floresta virgem em torno do equador ou nas calotes polares; mas amanhã, as últimas manchas brancas deste mapa admirável da saudade humana terão desaparecido» ${ }^{7}$. Daí que Jünger, no seu livro, se proponha analisar o modo como tudo o que é humano - a política, a profissão, a arte, a guerra, o vestuário, a saúde, o corpo, a ginástica - passa a ser cunhado pela unidade daquilo a que chama a "figura do trabalhador" naquilo que descreve como um "carácter total de trabalho" (totaler Arbeitscharakter); ou seja, o modo como as acções humanas, deixando de residir numa opção entre possibilidades diferenciadas, passam a ter o carácter de uma escolha fundamental entre a participação e a fuga. E é precisamente este o aspecto que pode caracterizar a "nova política" que se impõe hoje como uma crença a partir de um processo de globalização crescente e inevitável. Para os novos cidadãos da "nova política", pensada a partir da unificação global do espaço planetário, dir-se-ia que as suas escolhas e eventuais conflitos se realizam hoje, não entre opções políticas diferentes, mas entre a participação num processo imparável que se desenvolve automaticamente a partir de uma legalidade imanente, por um lado, ou uma fuga romântica e alienante diante da própria realidade, por outro. Partindo da unificação em rede do espaço planetário, instala-se a crença despolitizante - ou, usando a terminologia de Beck, "subpolitizante" - de que, no fundo, nenhuma escolha política faz diferença e de que, consequentemente, qualquer conflito político é hoje essencialmente indiferente.

A redução da escolha política à aceitação daquilo que é inevitável determina então hoje o modo como cada vez mais se caracteriza a cidadania em geral, sendo esta crença que está implícita no modo como as democracias liberais do mundo ocidental reconfiguraram as suas práticas políticas desde que, nas três últimas décadas, se conceberam a si

\footnotetext{
${ }^{7}$ Ernst Jünger, O Trabalhador, trad. Alexandre Franco de Sá, Lisboa, Hugin, 2000, p. $79-80$
} 
mesmas como um modelo institucional último e definitivo. Uma tal reconfiguração pode ser facilmente retratada. Antes de mais, ela poderse-á caracterizar pelo aspecto central que nela assume a ideia de escolha. Neste sentido, os cidadãos destas democracias podem ser caracterizados pela sua hostilidade a cargos não electivos e pela pura e simples identificação entre a liberdade e o direito de escolha. Contudo, esta "liberdade de escolha" alicerça-se cada vez mais no pressuposto de que aquilo entre o que se escolhe, não sendo propriamente igual, é algo cujas diferenças são irrelevantes; algo que se constitui, nessa medida, como essencialmente indiferente. Daí também que os cidadãos destas democracias sejam formados para se concentrarem exclusivamente na valorização do seu direito de decidir e de escolher, numa atenção que desvaloriza, ao mesmo tempo, a atenção dedicada ao cuidado pelo processo deliberativo no âmbito do qual são tomadas as decisões e feitas as escolhas. Uma tal desvalorização da dimensão deliberativa da decisão é algo essencialmente novo na história das democracias e caracteriza especificamente as democracias em que hoje geralmente vivemos. No âmbito daquilo a que se poderia chamar a política clássica ou tradicional, poder-se-ia dizer que a necessidade de uma convergência entre deliberação e decisão é algo óbvio e essencial em qualquer processo democrático. Já para Aristóteles, por exemplo, uma deliberação sem decisão seria algo próprio de seres humanos sem capacidade para o exercício da cidadania, como era o caso, segundo a sua representação, das mulheres; e uma decisão sem deliberação, por seu lado, longe de ser algo próprio de um homem livre, significaria antes apenas a acção impensada e dirigida por outrem, a acção de alguém que, incapaz de se confrontar com a realidade dos seus meios e dos seus fins, incapaz de se guiar a si mesmo, seria um escravo por natureza ${ }^{8}$. Dir-se-ia que os cidadãos das nossas democracias actuais, inseridos num processo de unificação planetária sobre o qual não deliberam e para o qual não existe qualquer alternativa política, estão, nesta medida, na mesma condição existencial do escravo aristotélico. E estão-no porque as escolhas políticas que são chamados ciclicamente a realizar, nas democracias em que se inserem, constituem não propriamente decisões deliberadas, pensadas crítica e responsavelmente, mas manifestações circunstanciais de emoções condicionadas por uma propaganda política cada vez mais indistinta do marketing comercial, manifestações que sabem que, em última análise, tudo se passará como é inevitável que passe.

Dir-se-ia, então, que os cidadãos das nossas actuais democracias são hoje cada vez mais preparados para reivindicarem o direito de escolher democraticamente sem pensar sobre o que escolhem, num exercício reivin-

${ }^{8}$ Cf. Aristóteles, Politica, 1254b23; 1260a12 
dicativo que abrange concomitantemente a recusa de qualquer responsabilidade por uma deliberação subjacente à sua própria decisão. E um tal exercício é possível precisamente porque a participação na vida política das sociedades democráticas tardias, determinadas pela consciência de um processo político para o qual não há qualquer alternativa, se caracteriza por aquilo a que se poderia chamar o carácter irrelevante e inconsequente de qualquer escolha possível. Se as grandes reivindicações democráticas foram, para muitos cidadãos no passado, o fruto da reivindicação de um futuro diferente do presente que viviam, dir-se-ia agora que, para os cidadãos da "nova política" das nossas democracias, as escolhas políticas se reduzem, cada vez mais, à mera formalidade procedimental que sustenta a manutenção do status quo, alimentando o trânsito para um futuro cuja característica fundamental é a sua essencial indistinção, a sua essencial indiferença, em relação ao próprio presente. É isso que permite a ironia de Pascal Bruckner, ao afirmar, acerca das eleições que ciclicamente legitimam as nossas democracias, que apenas «mudamos de pessoal político como fazemos zapping na televisão, por fadiga das mesmas imagens» ${ }^{9}$. E é esta transformação da escolha democrática numa espécie de ritual crepuscular desencantado, onde ciclicamente se confirma uma espécie de existência num "fim da história", assente na inexistência de possibilidades e de projectos políticos alternativos, que está na base do modo como cada vez mais se discute politicamente nas sociedades democráticas, em manifestações, movimentos de opinião e campanhas eleitorais que cultivam crescentemente decisões tomadas num registo essencialmente propagandístico, festivo e emocional que exclui, de uma forma crescente, a deliberação política. Dir-se-ia, então, que é a consciência de uma fundamental irrelevância e indiferença das escolhas e decisões políticas realizadas que pode permitir caracterizar a peculiar cidadania alimentada pelo mundo político que se apresenta como inevitável a partir do processo de globalização. E a caracterização desta peculiar cidadania, assim como da "nova política" que a acompanha como o seu pano de fundo, poder-se-ia aqui estender por três pontos fundamentais que importa enumerar especificamente.

Em primeiro lugar, uma tal cidadania pode ser caracterizada não só por um crescente abandono da participação política, apenas quebrado pela ocorrência pontual de fenómenos de entusiasmo colectivo promovidos mediaticamente, mas sobretudo por uma descrença crescente nas instâncias que, na vida política democrática, têm por incumbência precisamente representar o momento deliberativo dos processos de decisão. É por isso que, ao longo do século XX, os debates parlamentares se foram gradual-

${ }^{9}$ Pascal Bruckner, La mélancolie démocratique, Paris, Seuil, 1992, p. 61. 
mente perdendo como debates críticos e exercícios de persuasão, quer transformando-se em negociações partidárias nas quais já ninguém espera convencer ninguém, mediante a troca de argumentos racionais, quer abrindo caminho, nesta medida, para uma transferência do poder legislativo para instâncias meramente governamentais e executivas. É neste contexto de um crescente descrédito das instituições parlamentares que se pode compreender, em última análise, o processo estudado por Clinton Rossiter de uma progressiva transferência para as instâncias executivas do poder não só de governar, mas também de legislar ${ }^{10}$. E é neste mesmo enquadramento de um crescimento do poder dos executivos governamentais em detrimento do poder legislativo dos parlamentos que um pensador como Giorgio Agamben pode falar numa concentração de poder nos governos, e numa arbitrariedade crescente das suas decisões, que torna cada vez mais indistintas a excepção e a normalidade, transformando crescentemente as medidas arbitrárias, avulsas e excepcionais tomadas em situações de crise no paradigma pelo qual se legisla e governa nos Estados contemporâneos, «mesmo nos chamados democráticos» ${ }^{11}$. É neste sentido que Agamben pode caracterizar a cidadania vivida nestas sociedades como uma "vida nua", como uma vida análoga à vida simplesmente desprotegida dos refugiados e dos apátridas, tal como foi caracterizada pelos conhecidos passos de Hannah Arendt em As Origens do Totalitarismo ${ }^{12}$ : uma vida puramente exposta, sem mediações protectoras, à acção de um poder que, nessa medida, assume crescentemente as características do poder em estado puro com que Michel Foucault assinalou a intervenção de um "poder biopolítico".

Independentemente do acerto das análises de Agamben, em particular do carácter problemático da sua remissão para o conceito de soberania para a descrição do poder que se exerce sobre a "vida nua", o certo é que os cidadãos das nossas democracias são, de facto, preparados para valorizar crescentemente as decisões tomadas por executivos dinâmicos, cuja rapidez é conquistada sobretudo à custa do debate, da crítica e, portanto, da racionalidade deliberativa capaz de distinguir uma verdadeira decisão política de uma medida avulsa meramente arbitrária. Se os parlamentos foram pensados classicamente como as instâncias deliberativas nas quais se debate e se raciocina criticamente em função de uma projecção prospectiva dos futuros possíveis, dir-se-ia que, para cidadãos que habitam

${ }^{10}$ Cf. Clinton Rossiter, Constitutional Dictatorship, New Brunswick e Londres, Transaction, 2004.

${ }^{11}$ Cf. Giorgio Agamben, Stato di eccezione, Turim, Bollati Boringhieri, 2003, p. 11.

12 Cf. Giorgio Agamben, O poder soberano e a vida nua, trad. António Guerreiro, Lisboa, Presença, 1998, p. 126 ss. 
um mundo político cujo futuro já não é pensado como sendo constituído por diversas alternativas possíveis, os parlamentos não podem deixar de perder o sentido que lhes atribui a sua identidade tradicional. Num mundo globalizado, num espaço totalmente unificado e cuja "mobilização" - para usar a terminologia de Jünger - é cada vez mais veloz, os cidadãos não podem deixar de se caracterizar pela perda de sensibilidade em relação à morosidade do debate racional, da crítica prospectiva e dos raciocínios deliberativos. E é esta perda de sensibilidade que, antes de mais, determina a desvalorização política crescente do argumento racional em benefício de emoções mobilizadoras, assim como o abandono geral dos grandes debates políticos em torno de projecções do futuro, e de representações do vindouro, em benefício da rapidez da tomada de medidas exigidas conjunturalmente pelas circunstâncias de um mundo que se transforma com uma aceleração cada vez maior. É neste sentido que William Scheuerman pode escrever, ao tentar retratar os efeitos daquilo a que chama uma "aceleração do tempo social" sobre os processos deliberativos: «O beneficiário mais provável das recentes mudanças nos horizontes temporais da actividade humana é o executivo unitário, cujos contornos temporais contemporâneos e de alta velocidade parecem deixar especialmente bem apetrechado para o processo de decisão num ambiente social de correspondente alta velocidade» ${ }^{13}$. E é nestas mudanças recentes que se pode, por seu lado, encontrar o esclarecimento do aparente paradoxo verificado por Marcel Gauchet, o qual explicitamente se interroga sobre o facto de uma sociedade cada vez mais individualista, uma sociedade na qual os indivíduos descrêem da relevância da sua participação política, se caracterizar politicamente, ao mesmo tempo, por uma concentração crescente do poder nas mãos dos executivos governamentais e administrativos. Como escreve Gauchet, na verificação deste aparente paradoxo: «A inegável latitude adquirida pelos agentes individuais sobre todos os planos de nenhum modo impediu, mas, pelo contrário, favoreceu regularmente a constituição, à parte e acima da esfera da autonomia civil, de um aparelho administrativo que toma conta, cada vez mais larga e minuciosamente, da orientação colectiva» ${ }^{14}$.

Uma segunda característica da cidadania nossa contemporânea articula-se imediatamente com a desvalorização das instituições políticas representantes de momentos deliberativos, que acabámos de mencionar. A deliberação é um processo lento, no qual o pensamento procura ponderar todas

13 William Scheuerman, Liberal Democracy and the Social Acceleration of Time, Baltimore e Londres, The Johns Hopkins University Press, 2004, p. 45.

14 Marcel Gauchet, La démocratie contre elle-même, Paris, Gallimard, 2002, p. 20. 
as variáveis e abranger numa perspectiva prospectiva, tanto quanto possível, uma situação real que tem presente. Por seu lado, a capacidade de deliberar também não nasce espontaneamente no homem, mas cultiva-se através de um processo igualmente demorado no qual o homem vai amadurecendo e se vai tornando mais adulto, mais capaz e mais responsável. É a este processo lento que tradicionalmente se chamou o cultivo do carácter no homem através da prática da virtude. E é esta perspectiva sobre a maturidade e a lenta modulação do carácter humano, através da aprendizagem e de práticas repetidas ao longo de um tempo demorado, que vai perdendo, para o cidadão típico das sociedades em que vivemos, o seu sentido fundamental. Assim, inclinados para valorizar a resposta rápida em detrimento da decisão deliberada e pensada, tais cidadãos vão desvalorizando gradualmente, na sua própria formação e educação, os elementos que se ligam à aquisição da maturidade e ao cultivo lento de virtudes.

Uma tal desvalorização corresponde em geral, nas sociedades nossas contemporâneas, a uma transformação gigantesca de práticas educativas, através da qual a escola deixa de servir para introduzir os alunos num ambiente socialmente maduro e culturalmente elevado, passando a cumprir o papel de uma instância de socialização na qual os estudantes são chamados sobretudo a expressar emotivamente aquilo que já sempre são e sentem. É neste sentido que Jean-Claude Michéa tem razão ao caracterizar uma tal transformação como um "ensino da ignorância": uma ignorância que serve agora a construção do novo tipo de homem erguido pelas nossas sociedades pós-deliberativas. Como escreve Michéa: «É claro, de facto, que a transmissão custosa de saberes reais - e, a fortiori, críticos -, assim como a aprendizagem de comportamentos cívicos elementares, ou mesmo, muito simplesmente, o encorajamento da verticalidade e da honestidade, não oferece nenhum interesse para o sistema, e pode mesmo representar, em certas circunstâncias políticas, uma ameaça para a sua segurança. É evidentemente para esta escola do grande número que a ignorância deverá ser ensinada de todas as maneiras convenientes. Ora, isso é uma actividade que não é óbvia, e para a qual os professores tradicionais estavam até agora, apesar de certos progressos, muito mal formados. O ensino da ignorância implicará então necessariamente que estes se reeduquem, isto é, que se os obrigue a "trabalhar de outra maneira" sob o despotismo esclarecido de um exército poderoso e bem organizado de especialistas em "ciências da educação"» ${ }^{15}$. Numa tal atmosfera educativa, os novos cidadãos são, no fundo, formados para perderem a noção de que a sua vida é um "devir" no qual eles próprios

15 Jean-Claude Michéa, L'enseignement de l'ignorance, Paris, Climats, 2006, pp. 46-47. 
amadurecem e moldam o seu carácter, e para se conceberem como se fossem já uma identidade original, imutável e intemporal que apenas reivindica, na sua existência social, o direito de se expressar tal como é. É neste sentido que se poderia dizer que os cidadãos da "nova política" que se nos depara são cada vez mais cidadãos como que infantilizados, concebendo-se cada vez mais como uma espécie de crianças que já não querem amadurecer nem crescer, e que a criança se converte, como escreve Pascal Bruckner em A tentação da inocência, no "destino do homem". Torna-se aqui manifesto que a principal característica deste novo cidadão infantilizado consiste na negação da sua existência como um devir: «Já não "devenho", sou tudo aquilo que devo ser em qualquer instante, posso aderir sem remorsos às minhas emoções, invejas, fantasias. [...] Não ponho quaisquer limites aos meus apetites, já não tenho de me construir, isto é, de introduzir uma distância entre mim e mim» ${ }^{16}$.

Finalmente, em terceiro e último lugar, poderíamos aqui evocar, como consequência inevitável da análise levada a cabo até agora, a conversão dos cidadãos infantilizados que descrevemos em cidadãos incapazes de realizar escolhas propriamente políticas, ou seja, de encarar dilemas políticos e de se confrontar com a exigência política de decisões reais. $\mathrm{Na}$ medida em que o mundo político deixa de ser hoje um mundo de confrontação e de projectos em conflito, passando a ser o âmbito no qual um movimento humanamente imparável de "mobilização total" desenvolve o seu rumo inevitável, e na medida em que, inserido neste mesmo mundo político, os homens já não são chamados a encarar a sua vida como um devir que lhes forma o carácter ou como uma aprendizagem que os transforma, concebendo-se antes, cada vez mais, como indivíduos centrados sobre si e vinculados apenas à individualidade das suas idiossincrasias, as escolhas e decisões políticas que são feitas são agora determinadas exclusivamente por referência a esta mesma individualidade. Tal quer dizer que as escolhas e decisões políticas são tomadas por estes indivíduos sem qualquer referência à própria realidade efectiva que lhes determina, antes de mais, a possibilidade ou a impossibilidade. E é esta característica que torna hoje cada vez mais popular o conhecido lema do Maio de 68: "sejamos realistas, exijamos o impossível!". Assim, se os cidadãos das nossas "sociedades globalizadas" realizam hoje decisões e escolhas que têm como referência exclusivamente os seus princípios próprios, com os quais não admitem transigir, dir-se-ia que eles constituem aquilo a que Rafael del Águila chamou, com pertinência, um conjunto de "cidadãos impecáveis" cuja característica fundamental consiste em não saber distinguir

16 Pascal Bruckner, La tentation de l'innocence, Paris, Grasset, 1995, p. 107. 
entre as decisões políticas propriamente ditas e a simples afirmação de princípios morais. É por isso que del Águila caracteriza tais cidadãos como «cidadãos auto-satisfeitos irresponsáveis pelas decisões, crentes na fé da harmonia política, incapazes de enfrentar as cisões a que as decisões públicas conduzem, sem possibilidade de desenvolver a sua autonomia de juízo no meio da auto-complacência em que se movem, sem qualquer tensão cidadã e em permanente menoridade, vivendo o sonho sem limites da adolescência política em que tudo é possível e, além disso, o é sem custos» ${ }^{17}$. Por outras palavras, os "cidadãos impecáveis", infantilizados e descrentes em relação à mínima relevância das suas decisões políticas, surgem agora como indivíduos fiéis a si mesmos e aos seus princípios, reivindicativos em relação ao direito de expressão desses mesmos princípios e inocentes em relação a quaisquer acontecimentos políticos que possam exigir a sua relativização. A despolitização geral - ou, o que é o mesmo, a emergência de uma "nova política" que se apresenta como inevitavelmente proveniente da globalização - tem assim como consequência última a emergência de uma "idade da inocência" na qual a exigência de uma cidadania centrada na deliberação e no cuidado pelas decisões políticas dos cidadãos é substituída por uma vida política marcada por um peculiar modo político de pensar: um modo de pensar constituído por uma convergência paradoxal entre o cepticismo e a descrença, por um lado, e a infantilidade e a inocência, por outro; um modo de pensar que constitui cidadãos caracterizados quer como centrados na afirmação intransigente dos seus princípios próprios quer como incapazes de mediar esses mesmos princípios através da sua confrontação com a realidade.

Nas democracias tardias do mundo ocidental, poderíamos dizer que o problema mais fundamental das suas instituições consiste hoje na sua transformação invisível no sentido justamente da promoção da "idade da inocência" marcada pela proliferação desta cidadania menorizada e infantil. Dir-se-ia que hoje, nestas democracias, as instituições políticas fundamentais, desde os parlamentos aos governos, desde os poderes mediáticos aos partidos, se convertem em instâncias promocionais desta "idade da inocência". E o modo como tal promoção é levada a cabo pode ser facilmente descrito. Convertidos em "cidadãos impecáveis" pela atmosfera política e mediática das sociedades em que se inserem, os indivíduos presentes nestas mesmas sociedades tornam-se cada vez mais assertivos e intransigentes relativamente à afirmação dos seus princípios próprios. E tal quer dizer que, para tais indivíduos, se torna necessário, para a sustentação da sua intransigência imaculada e da sua inocência impecável,

${ }^{17}$ Rafael del Águila, La senda del mal. Política y razón de Estado, Madrid, Taurus, 2000, p. 22 . 
a existência de um mecanismo catártico que canalize para o exterior a culpa e a mácula que advêm de qualquer confrontação com a realidade fáctica. Nas nossas democracias actuais, dir-se-ia que um tal mecanismo é assegurado precisamente pelos agentes políticos - pelos governantes, políticos profissionais e líderes partidários - que ocupam o lugar daquele cuja função consiste absorver a culpa e a transigência que cidadãos inocentes e imaculados afastam catarticamente de si.

As democracias constituem-se especificamente como regimes cujas elites políticas assumem aquilo a que se poderia chamar uma função sacrificial. Elas deixam de se organizar segundo o critério "aristocrático" (timocrático ou elitista) da escolha de homens cuja governação se acredite poder fazer alguma diferença, ou da eleição de governantes cuja decisão possa ser, em algum âmbito relevante, melhor que a dos seus concorrentes. Se, no nosso mundo pós-político, nenhuma escolha faz realmente diferença e todas as decisões políticas são, nessa medida, indiferentes, os ocupantes das instâncias de poder são igualmente indiferentes e as elites políticas não têm outra função senão ocupar o lugar daquela entidade cuja culpa absoluta assegura a inocência e o carácter impecável de todos os outros. Assim, longe de se constituírem como os "melhores" de uma selecção "aristocrática", tais elites constituem agora uma espécie de "oligarquia cacocrática" (o adjectivo grego kakos é o antónimo de aristos) na qual a "classe política" desempenha o papel de quem existe para ser criticado, julgado ou mesmo criminalizado, surgindo como a vítima sacrificial ou o bode expiatório que, como explicou René Girard ${ }^{18}$, tem por missão restabelecer o equilíbrio social através da concentração de toda a violência sobre si, ou seja, através da assunção de uma mácula absoluta que possibilita a restauração da inocência de todos os outros. É por esta razão que as nossas democracias, no nosso mundo pós-político, se traduzem numa ritualização de ciclos constituídos pelas derrotas eleitorais de governantes e partidos, substituídos por outros que, não sendo propriamente iguais, são considerados genericamente, em relação aos primeiros, essencialmente indiferentes. E é sobretudo diante desta metamorfose das democracias ocidentais em oligarquias cacocráticas que se pode adquirir a consciência da urgência de pensar em torno de um modo de sair do discurso pós-político que a sustenta. Dir-se-ia que, diante de um discurso que assinala a despolitização e a unificação do espaço planetário como um destino inevitável, se torna necessário precisamente pensar as condições para que uma repolitização se torne possível.

18 Cf. René Girard, La violence et le sacré, Paris, Grasset, 1996, p.127. 